Communication

[Comunicação]

\title{
Utilização de fenbendazole e da associação febantel, pamoato de pirantel e praziquantel no controle de oxiurídeos em gerbis
}

\author{
[Use of fenbendazole and the febantel, pamoato of pirantel and praziquantel association in the \\ control of oxiurids in jirds]
}

H.H.S. Machado, F.F. Gomes; V.R.S. Fiuza, R.S. Toledo; F. C.R. de Oliveira

Universidade Estadual do Norte Fluminense Darcy Ribeiro - UENF

28013-600 - Campos dos Goytacazes, RJ

Gerbis (Meriones unguiculatus) são animais de biotério bastante utilizados para estudos em parasitologia e testes de triagem farmacológica (Pinto et al., 2003). Dentre os mais importantes e freqüentes helmintos que infectam naturalmente esses hospedeiros estão os oxiurídeos Aspiculuris tetraptera, Syphacia obvelata, Syphacia muris e Dentostomella translucida (Bazzano et al., 2002), os quais constituem um persistente problema para o manejo de roedores de laboratório (Wightman et al., 1978; Solas, 1999; Pinto et al., 2003). Tais espécies apresentam ciclo direto e parasitam intestino delgado, cólon, ceco e reto do hospedeiro.

Os ovos são eliminados no ambiente através das fezes ou depositados na região perianal do hospedeiro. São muito resistentes no ambiente, permanecendo viáveis por semanas na cama de maravalha e, ainda, por serem muito leves, são facilmente carreados por aerossóis, favorecendo a disseminação dos agentes parasitas. A infecção de animais de laboratório ocorre após a ingestão de ovos embrionados e geralmente a doença é subclínica; no entanto, prolapso retal, intussucepção, impactação fecal e irritação perianal podem ocorrer (Solas, 1999). Gerbis são susceptíveis à infecção por $S$. obvelata e $A$. tetraptera de ratos e camundongos, enquanto ratos são resistentes à infecção por $D$. translucida de gerbis (Pinto et al., 2003). Já a espécie $S$. muris pode transitar entre gerbis, ratos e hamster (Ross et al., 1980).
O fenbendazole incorporado à alimentação é citado para controle químico de oxiurídeos em animais de laboratório (Wilkerson et al., 2001). A combinação das três bases, pamoato de pirantel, febantel e praziquantel, mostra eficácia para cães e gatos (Booth e McDonald, 1992). Dessa forma, este trabalho teve por objetivo avaliar a utilização de um produto comercial à base de fenbendazole e outro à base de pamoato de pirantel, febantel e praziquantel no controle de oxiurídeos em gerbis de laboratório naturalmente infectados.

O experimento foi realizado com 18 gerbis criados em biotério, de aproximadamente dois meses de idade, naturalmente infectados por oxiurídeos, estes foram distribuídos em três grupos contendo seis espécimes cada um. Os grupos foram padronizados de acordo com o peso vivo, que variou entre 48,30g e 79,26g. Três animais do mesmo plantel que tiveram morte natural antes do início do experimento foram necropsiados, e os helmintos adultos recolhidos confirmaram a identificação das espécies dos oxiurídeos.

A investigação sobre a infecção parasitária pelos nematódeos foi realizada pela identificação dos ovos nas fezes, por meio do método de Willys, e pelo cálculo de ovos por grama de fezes (OPG), pelo método de Gordon e Withlock modificado (Ueno e Gonçalves, 1998). Foram realizados exames coproparasitológicos antes da medicação e aos 7, 14 e 21 dias após o tratamento (DAT). 
Os animais do primeiro grupo tratado receberam a base fenbendazole ${ }^{1}$, na dose única de $0,1 \mathrm{ml}$, correspondendo a $10 \mathrm{mg}$ do princípio ativo. Os do segundo grupo tratado receberam a associação febantel, pirantel e praziquantel ${ }^{2}$, na dose única de $0,1 \mathrm{ml}$, correspondendo a $1,5 \mathrm{mg}$ de feantel, $1,44 \mathrm{mg}$ de pirantel e $0,5 \mathrm{mg}$ de praziquantel. Os do terceiro grupo não receberam tratamento e serviram como controle positivo. A administração dos medicamentos foi feita por via oral através de sonda de gavage. A eficácia dos tratamentos, expressa em porcentagem, foi calculada dividindo-se a diferença entre $\mathrm{s}$ números médios de OPG dos grupos-controle e tratado pelo número médio de OPG do grupocontrole.

Após o exame das 18 amostras fecais na fase inicial do experimento, constatou-se que 100\% encontravam-se positivas para oxiurídeos, o que confirma as informações dos autores que dizem ser as oxiuríases as helmintoses mais importantes e freqüentes que acometem os animais de laboratório (Wightman et al., 1978; Solas, 1999;
Pinto et al., 2003). Nesta pesquisa, não foram observados sinais aparentes de reações adversas aos medicamentos nos animais tratados.

Os dados relativos ao número médio de ovos por grama de fezes, bem como a eficácia dos protocolos testados são expressos na Tab. 1. Os resultados indicaram que a eficácia do fenbendazole no controle das infecções foi mais satisfatória nos primeiros sete dias após o tratamento e diminuiu com o tempo. Quanto à associação de bases, observou-se que a eficácia foi inferior no sétimo DAT, mas manteve-se mais alta durante as duas últimas semanas após o tratamento, embora não tenha ocorrido a total eliminação dos parasitas. O decréscimo na taxa de eficácia pode ser atribuído também à ocorrência de novas infecções durante o ensaio, por ingestão de ovos embrionados da região perianal, ingestão de alimentos ou água contaminados por ovos embrionados e retroinfecção, quando ovos eclodem na região perianal, e as larvas migram de volta para o cólon (Solas, 1999).

Tabela 1. Resultados coproparasitológicos para ovos de oxiurídeos em gerbis naturalmente infectados, pelo método de Gordon e Whitlock modificado

\begin{tabular}{llcccc}
\hline \multirow{2}{*}{ Grupo } & Dados & \multicolumn{3}{c}{ Dias após o tratamento } \\
\cline { 3 - 6 } Controle & Animais positivos & 6 & 7 & 14 & 21 \\
& OPG mínimo e máximo & $100-2000$ & $200-2000$ & $150-2000$ & $200-1300$ \\
& OPG médio & 1050 & 1100 & 858 & 816 \\
& Erro padrão da média & 338 & 282 & 315 & 156 \\
Tratado $^{a}$ & Animais positivos & 6 & 1 & 3 & 4 \\
& OPG mínimo e máximo & $100-2100$ & 200 & $200-400$ & $200-1300$ \\
& OPG médio & 925 & 200 & 300 & 500 \\
& Erro padrão da média & 274 & 0 & 58 & 267 \\
Tratado $^{b}$ & Eficácia & - & $81,82 \%$ & $65,03 \%$ & $38,73 \%$ \\
& Animais positivos & 6 & 1 & 2 & 2 \\
& OPG mínimo e máximo & $300-2100$ & 300 & $200-250$ & $100-700$ \\
& OPG médio & 1017 & 300 & 225 & 400 \\
& Erro padrão da média & 329 & 0 & 25 & 301 \\
& Eficácia & - & $72,73 \%$ & $73,78 \%$ & $50,98 \%$ \\
\hline
\end{tabular}

${ }^{a}$ Animais tratados com fenbendazole ${ }^{1}{ }^{b}$ Animais tratados com a associação febantel, pirantel e praziquantel ${ }^{2}$.

A ação medicamentosa do princípio fenbendazole deve-se primariamente à interferência no metabolismo gerador de energia do parasita e secundariamente à inibição do transporte da glicose. Na maioria dos tecidos de animais que recebem essa droga, os resíduos do

\footnotetext{
${ }^{1}$ Panacur, Intervet, Brasil.

${ }^{2}$ Printel Plus, Centagro, Brasil.
} 
fenbendazole se aproximam do limite mínimo de detecção em dois dias, sugerindo um período curto de atuação do princípio ativo (Booth e McDonald, 1992). Essa base já foi citada como eficaz no controle das oxiuríases por administração oral de $150 \mathrm{ppm}$ pré-misturado à dieta e associada à aplicação tópica de ivermectina (Wilkerson et al., 2001). O sal pamoato de pirantel é fracamente solúvel em água, o que oferece a vantagem da absorção reduzida no intestino, permitindo que a droga atinja os oxiurídeos na porção final do intestino grosso, sendo, especialmente, benéfico para o uso contra esste grupo de helmintos. Tanto o pamoato de pirantel como o febantel apresentam ação de curta duração, tendo sua eliminação completa em fezes e urina no prazo de três a quatro dias (Booth e McDonald, 1992).

Com os resultados deste ensaio e com base nos ciclos parasitários dos três gêneros de oxiurídeos envolvidos, sugere-se que, para o controle ser mais efetivo, o protocolo deve basear-se em pelo menos três aplicações da dose dos medicamentos testados, com intervalos de 10 dias, associadas a condições adequadas de higiene no manejo.

Palavras-chave: gerbis, anti-helmíntico

\begin{abstract}
Eighteen jirds were equally distributed in two treated and one control groups. The commercial products to the fenbendazole base (10mg) and the association of febantel (1.5mg), pirantel (1.44mg) and praziquantel (0.5mg) were orally administred in the concentration of $0.1 \mathrm{ml}$ in each group. The effectiveness of febendazole against oxiurids was 81.8\%, 65.0 and $38.7 \%$ and for the association of febantel, pirantel and praziquantel was $72.7 \%, 73.8 \%$ and $51.0 \%$ on days 7,14 and 21 , respectively. Three applications of that dose of the tested medications, within intervals of 10 days, associated to hygiene, are recommended.
\end{abstract}

Keywords: jirds, anthelmintic

\section{REFERÊNCIAS BIBLIOGRÁFICAS}

BAZZANO, T.; RESTEL, T.I.; PINTO, R.M. et al. Patterns of infection with the nematodes Syphacia obvelata and Aspiculuris tetraptera in conventionally maintained laboratory mice. Mem. Inst. Oswaldo Cruz, v.97, p.847-853, 2002.

BOOTH, N.H.; McDONALD, L.E. Farmacologia $e$ terapêutica em veterinária. 6.ed. Rio de Janeiro: Guanabara Koogan, 1992. 997p.

PINTO, R.M.; GOMES, D.C.; NORONHA, D. Evaluation of coinfection with pinworms (Aspiculuris tetraptera, Dentostomella translucida, and Syphacia obvelata) in gerbils and mice. Contemp. Top. Lab. Anim. Sci., v.42, p.46-48, 2003.

ROSS, C.R.; WAGNER, J.E.; WIGHTMAN, S.R.; DILL, S.E. Experimental transmission of Syphacia muris among rats, mice, hamsters and gerbils. Lab. Anim. Sci., v.30, p.35-37, 1980
SOLAS, G.V. Implications of infectious agents on results of animal experiments - Oxyurina (Pinworms). Lab. Anim., v. 33, suppl. 1, p.85- 86, 1999.

TAFFS, L.F. Pinworm infections in laboratory rodents: a review. Lab. Anim., v.10, p.1-13, 1976.

UENO, H.; GONÇALVES, P.C. Manual para diagnóstico das helmintoses de ruminantes. 4.ed. Tokyo: Japan International Cooperation Agency, 1998. 143p.

WIGHTMAN, S.R.; PILITT, P.A.; WAGNER, J.E.; Dentostomella translucida in the Mongolian gerbil (Meriones unguiculatus). Lab. Anim. Sci., v.28, p.290296, 1978.

WILKERSON, J.D.; BROOKS, D.L.; DERBY, M.; GRIFFEY, S.M. Comparison of practical treatment methods to eradicate pinworm (Dentostomella translucida) infections from Mongolian gerbils (Meroines unguiculatus). Contemp. Top. Lab. Anim. Sci., v.40, p.31-36, 2001. 